\title{
Cytoprotective mechanisms in cultured cardiomyocytes
}

\section{Hari S. Sharma, ${ }^{1}$ Joachim Stahl, ${ }^{2}$ Dirk Weisensee ${ }^{3}$ and Iris Löw- Friedrich ${ }^{3}$}

${ }^{\prime}$ Cardiovascular and Molecular Biology Laboratory, Institute of Pharmacology, Erasmus University, Rotterdam, The Netherlands; 'Max-Delbrïck-Center for Molecular Medicine, Berlin, Germany; ${ }^{3}$ Center for Internal Medicine, J. W. Goethe University Hospital, Frankfurt am Main, Germany

\begin{abstract}
Tumor necrosis factor- $\alpha$ (TNF- $\alpha$ ), a potent cytokine mainly secreted by macrophages exerts pleiotropic effects on different cell types. However, the intracellular mediators of its action are not yet well characterized. To get an insight into endogenous cytoprotective mechanisms, we developed an in vitro model based on cultured cardiomyocytes treated with TNF- $\alpha$ at which we examined gene expression of heat shock proteins (HSP-27, HSP-70 and ubiquitin). Cardiomyocytes were isolated from the hearts of 18 day old fetal mice by enzymatic dissociation and grown in minimum essential medium containing $10 \%$ fetal calf serum. Spontaneously contractile cells were serum deprived for $24 \mathrm{~h}$ and treated with TNF- $\alpha$ ( $25 \mathrm{ng} / \mathrm{ml})$ for $1,2,4,6,8,12$, and $24 \mathrm{~h}$ After each incubation, cells were processed to extract total proteins for Western and total RNA for Northern blot analyses. TNF- $\alpha$ induced arrhythmias and cessation of spontaneous contractions in a concentration and time dependent manner. Steady state (ubiquitin) or undetectable mRNA levels (HSP-27, HSP-70) were drastically induced ( $>4$ fold for all three genes vs untreated control cells) by TNF- $\alpha$, reaching maximal values between $6-8 \mathrm{~h}$ of stimulation. Thereafter, the expression of these stress genes declined but remained elevated as compared to control. By Western blot analysis, we found increased multiple bands of ubiquitin protein conjugates in TNF- $\alpha$ treated cells whereas no significant change in HSP-27 protein accumulation until $12 \mathrm{~h}$ was observed as compared to control. $24 \mathrm{~h}$ of TNF- $\alpha$ incubation resulted in partial cellular necrosis. Our results indicate that TNF- $\alpha$ induces in cardiomyocytes transiently gene expression for cytoprotective molecules like HSP-27, HSP-70 and ubiquitin, suggesting these stress proteins to participate in subsequent defense mechanisms, for example in postischemic myocardial recovery. (Mol Cell Biochem 160/161: 217-224, 1996)
\end{abstract}

Key words: TNF- $\alpha$, heat shock proteins, cardiomyocytes, cytoprotection

\section{Introduction}

Dysfunction of the coronary endothelium as well as injury to cardiac muscle cells are the consequences of myocardial ischemia and reperfusion. A number of factors including various cytokines like TNF- $\alpha$ are released in the postischemic myocardium [1-3]. These ischemia induced cytokines may mimic the local cellular injury and may contribute in altering molecular phenotype of the postischemic myocardium. Increase in local expression as well as in circulating TNF- $\alpha$ has been reported in experimental animals and in patients with myocardial ischemia and infarction $[1,3]$. In a recent study, pretreatment of rat hearts with TNF- $\alpha$ was found to be protective from ischemia and reperfusion injury [4]. However, in the normal heart, TNF- $\alpha$ may exert negative inotropic effects by directly altering intracellular calcium homeostasis in a concentration and time dependent manner [5]. We have shown earlier that perfusion of spontaneously contracting cultures of cardiomyocytes with a high dose of TNF- $\alpha$ $(10,000$ units $/ \mathrm{ml})$ led to arrhythmias with time and complete cessation of spontaneous contractions followed by severe loss of myocyte inotropy [6]. More recently, we have reported that TNF- $\alpha$ as well as interleukins (IL-2, IL-3, IL-6) induce formation of stress proteins in cultured cardiomyocytes $[7,8]$. 
We hypothesize that TNF- $\alpha$ stimulates cytoprotective mechanisms in cardiomyocytes, and such mechanisms can be examined by investigating the expression pattern of various heat shock/stress protein genes.

TNF- $\alpha$, a multipotent cytokine, originally known for its anti-tumor activity, has now been implicated in several biologic processes including inflammation, immunoregulation, cytotoxicity, cytoprotection and angiogenesis [9-11]. TNF$\alpha$ is predominantly secreted by activated monocytes and it exerts pleiotropic effects on different cell types $[10,12]$. However, the intracellular mediators of its action are not yet well known. Biological effects of TNF- $\alpha$ in the target cell are initiated by its binding to high affinity cell surface receptors [13-15]. TNF receptors are expressed on the membranes of virtually all somatic cell types $[13,14]$. TNF receptors channel signals to cytoplasm and nucleus, and thereby initiate profound alterations in the metabolic pathway and nuclear transcription [13-16]. Two immunologically distinct TNF receptors of $55 \mathrm{kDa}$ and $75 \mathrm{kDa}$ apparent molecular mass have been identified and characterized $[13,14]$. Many studies have demonstrated that TNF- $\alpha$ induces phosphorylation of a stress protein of about $28 \mathrm{kDa}$ in different cell types [7, 18-20] and this phosphorylation results from stimulation of $G$ protein coupled signal transduction involving the mitogen activated protein (MAP) kinase cascade [17, 21]. Furthermore, TNF- $\alpha$ may function as indirect angiogenic growth factor because it is a potent noncytotoxic growth inhibitor for endothelial cells in vitro, and enhances neovascularization in vivo [11], probably by inducing a potent angiogenic polypeptide such as vascular endothelial growth factor [22].

Heat shock proteins (HSPs) are a group of highly conserved proteins that can be stimulated by heat shock and other environmental and pathophysiological stresses [23-29]. Also glucose regulated proteins (GRPs), ubiquitin, $\alpha \beta$-crystalline and heme oxygenase [24-26, 28-33] are included in the group of HSPs. These proteins participate in cellular defense mechanisms and enable cells to survive and recover from stressful conditions $[23,26,27,34]$. The proteins of the HSP70 family are relatively well characterized; they bind to ATP and help in posttranslational import of proteins into endoplasmic reticulum and mitochondria $[23,26,35]$. The small heat shock protein HSP-27 migrates to the nucleus upon stress, can act as a molecular chaperone and plays an important role in signal transduction and drug resistance [20, 24-27]. Ubiquitin is a stress protein of $8 \mathrm{kDa}$ that also belongs to the small heat shock family of proteins and contributes to ATP dependent non-lysosomal protein degradation $[30,33,36]$.

It is believed that the heart has its own endogenous system(s) for protecting itself against ischemia-reperfusion injury, and a number of HSPs that may act as chaperones in saving vital cellular proteins from degradation have been proposed $[24-29,34,35]$. Over the last many years, we have been interested in characterizing molecules in the post- ischemic myocardium that may play important roles in cellular defense, in particular against ischemia $[8,22,25,29$, $33,37]$. In the present study we attempted to evaluate TNF$\alpha$ induced endogenous cytoprotective mechanisms in cultured cardiomyocytes. We developed an in vitro model based on cardiomyocytes treated with an adequate amount of TNF$\alpha$ and examined the expression patterns of HSP-27, HSP-70 and ubiquitin at mRNA and protein levels.

\section{Materials and methods}

\section{Cell culture}

Cardiomyocytes were isolated from hearts of 18 day old fetal mice by the method described elsewhere $[6,7]$. Briefly, small pieces of fetal cardiac tissue were subjected to trypsin (Biochrom KG, Berlin, FRG) digestion (final concentration of trypsin $0.1 \%$ ) in calcium-magnesium free phosphate buffered saline (PBS, $140 \mathrm{mM} \mathrm{NaCl}, 2.6 \mathrm{mM} \mathrm{KCl}, 1.4 \mathrm{mM}$ $\mathrm{KH}_{2} \mathrm{PO}_{4}, 8 \mathrm{mMNa}_{2} \mathrm{HPO}_{4} \cdot 2 \mathrm{H}_{2} \mathrm{O}$ ). The supernatants of the first two digestion steps were discarded and thereafter supernatants of two trypsinization steps were collected. Trypsin was inactivated by dilution of the supernatants into equal volumes of ice-cold alpha medium supplemented with $20 \%$ fetal calf serum (FCS), penicillin ( $25 \mathrm{U} / \mathrm{ml})$, and streptomycin $(25 \mu \mathrm{g} / \mathrm{ml})$. All chemicals, antibiotics, and media were of tissue culture grade and procured from Sigma Chemie, Deisenhofen, FRG, or from Life technologies GmbH, Eggenstein, FRG. Cells were collected by centrifugation at $4^{\circ} \mathrm{C}$ in a Sorvall SS34 rotor at $1000 \mathrm{rpm}$ for $10 \mathrm{~min}$ and seeded in petri-dishes with a coverslip at the bottom. The cell number was determined in a Neubauer chamber and adjusted to 1.5 $\times 10^{6}$ cardiomyocytes per dish (Nunc, Denmark, diameter 6 $\mathrm{cm}$ ). The adherent cardiomyocytes were incubated for 2 days in alpha medium with $20 \% \mathrm{FCS}$ and another 2 days in Dulbecco's minimum essential medium (DMEM) with $10 \%$ FCS. Later on the cultures were transferred to L-valine deficient DMEM to prevent the growth of any fibroblasts. The cardiomyocytes which were spontaneously contractile (average frequency $86 \pm 16 \mathrm{cycles} / \mathrm{min}$ ) in culture were incubated for 5 days at $37^{\circ} \mathrm{C}$ in a humidified atmosphere with $5 \%$ $\mathrm{CO}_{2}$ prior to start of serum deprivation and incubations. The contractility of cardiomyocytes was followed in a microscope perfusion system at constant temperature of $37 \pm 0.1^{\circ} \mathrm{C}$ according to the method described earlier [6].

\section{Immunofluorescence staining}

In order to check the purity of cardiomyocytes, culture dishes were fixed in ice-old methanol/acetone $1: 1$ for $10 \mathrm{~min}$, 
washed with PBS and followed by incubation with anti-titin antibody (Boehringer Mannheim $\mathrm{GmbH}$, Mannheim, FRG) diluted in PBS with $0.5 \%$ bovine serum albumin (BSA) for $60 \mathrm{~min}$ at room temperature. After washing twice with PBS, slides were incubated with TRITC-conjugated secondary antibody against mouse IgG $(1: 10)$ for another $60 \mathrm{~min}$ at room temperature. The preparations were washed again, mounted and photographed under a fluorescence microscope (Axioskop, Zeiss, Oberkochen, FRG) using a Kodak Tri-X film (400 ASA). In addition, we also stained cardiomyocytes grown for 5 days in culture with anti-actin antibodies (Boehringer Mannheim GmbH, Mannheim, FRG) using rhodamine phalloidin. Photographs were taken by using a fluorescence microscope equipped with epi-illumination.

\section{$T N F-\alpha$ incubation}

Cultures of cardiomyocytes were serum deprived for $24 \mathrm{~h}$. and incubated with the recombinant TNF- $\alpha(25 \mathrm{ng} / \mathrm{ml}$, British Biotechnology Ltd., UK) for 1, 2, 4, 6, 8, 12 and $24 \mathrm{~h}$. TNF- $\alpha$ was directly added to the culture dishes without exchanging the medium to avoid any culture shock. We used $3 \times 10^{6}$ cardiac myocytes for each time point and repeated the experiments for at least three times. Cells were harvested after each incubation directly either in guanidinium isothiocyanate buffer [38] for isolation of total cellular RNA or in protein solubilization buffer [39] for protein assay.

\section{RNA isolation and Northern blot analysis}

Total cellular RNA was isolated from cardiomyocytes treated with TNF- $\alpha$ for different time periods by the method of Chomczynski and Sacchi [38]. RNA concentration was measured by optical density and the quality of RNA was tested on a denatured formaldehyde agarose gel. For Northern hybridization, $15 \mu \mathrm{g}$ of total RNA was denatured at $65^{\circ} \mathrm{C}$ in buffer containing formamide and ethidium bromide and electrophoresed on $1 \%$ agarose gel containing $2.2 \mathrm{M}$ formaldehyde $[25,33,37]$. RNA was transferred to Hybond-N membrane (Amersham Nederland B.V., Den Bosch, Holland) by vacuum blotting. Thereafter, filters were air-dried, UV crosslinked in a gene linker (Bio-Rad Laboratories B.V., Holland) and ribosomal RNA bands were marked under UV light. Blots were hybridized at $42^{\circ} \mathrm{C}$ in a buffer containing $50 \%$ deionized formamide, $1.0 \mathrm{M}$ sodium chloride, $1 \%$ sodium dodecylsulfate (SDS), $0.2 \%$ polyvinyl pyrrolidone, $0.2 \%$ ficoll, $0.2 \%$ bovine serum albumin, $50 \mathrm{mM}$ Tris-HCl ( $\mathrm{pH} 7.5$ ), $0.1 \%$ sodium pyrophosphate, $10 \%$ dextran sulfate and denatured salmon sperm DNA $(100 \mu \mathrm{g} / \mathrm{ml})$. Blots were hybridized with radiolabeled cDNA probes encoding HSP-27, HSP-70 and ubiquitin [36,
40, 41]. cDNA inserts were labeled employing a multiprime labeling system (Amersham Nederland BV, Den Bosch, Holland) to a specific activity of $10^{9} \mathrm{cpm} / \mu \mathrm{g}$ DNA using [ $\left[{ }^{32} \mathrm{P}\right]-$ dCTP $(3000 \mathrm{Ci} / \mathrm{mmol}$, Amersham Nederland BV, Den Bosch, Holland). Filters were washed at room temperature for $5 \mathrm{~min}$ in $2 \times \mathrm{SSC}(1 \times \mathrm{SSC}=0.15 \mathrm{M} \mathrm{NaCl}, 0.015 \mathrm{M}$ sodium citrate $)$ and $0.1 \% \mathrm{SDS}$ and at $55^{\circ} \mathrm{C}$ in $0.1 \times \mathrm{SSC}$ containing $0.1 \% \mathrm{SDS}$ for $20 \mathrm{~min}$. Subsequently, filters were wrapped in household plastic wrap and exposed to Kodak X-OMAT AR films (Kodak Nederland B. V., Odijk, Holland) at $-80^{\circ} \mathrm{C}$ for 1- 3 days. A glyceraldehyde-3-phosphate dehydrogenase (GAPDH) cDNA probe $(1.2 \mathrm{~kb}$ Pstl fragment of human cDNA, procured from ATCC, USA) was used to rehybridize membranes for reference purposes. Furthermore, filters were re-hybridized with a cDNA insert of 770 bp encoding $28 \mathrm{~S}$ rRNA in order to calculate the extent of induction of HSP expression after correcting the RNA loading differences. Hybridization signals on autoradiographs were quantified by video scanning in optical density mode using a Bioprofil version 4.6 computer program (Vilber Lourmat, France). Several exposures of the Northern blots were taken to ensure that quantitation of hybridization signals was in linear range. For normalization, optical density (O.D.) of hybridization signal for each gene was divided by O.D. of the corresponding GAPDH or $28 \mathrm{~S}$ rRNA signal. Induction of each gene was calculated and expressed as \% relative mRNA values (mean \pm S.E.M.) in TNF$\alpha$ treated cardiomyocytes as compared to control. Expression was statistically analyzed using student's " $t$ "-test and significance was accepted at $\mathrm{p} \leq 0.05$.

\section{Polyacrylamide gel electrophoresis and Western blot analysis}

After each incubation, medium was removed and cells were washed with PBS, harvested and sonicated in Laemmli buffer ( $1 \%$ SDS, $0.1 \mathrm{M}$ Tris-Cl, pH $6.8,20 \%$ glycerol, $0.001 \%$ bromophenol blue, $0.1 \mathrm{M}$ DTT and 5\% b-mercaptoethanol). Cell suspension was boiled for $5 \mathrm{~min}$ in a boiling water bath, centrifuged, and then cell debris were discarded and the supernatant collected. The protein concentration was measured in the supernatants according to the method of Lowry et al. [42] using bovine serum albumin as a standard. Samples of $20 \mu \mathrm{l}$ each were subjected to one-dimensional sodium dodecyl sulphate-polyacrylamide gel electrophoresis (SDSPAGE) in a discontinuous system using the method described by Laemmli [39]. The resolving gel concentration was $15 \%$ of the total acrylamide:bis-solution (37.5:1). The separated proteins were electrophoretically transferred according to the method of Towbin et al. [43] to a $0.45 \mu \mathrm{m}$ nitrocellulose membrane (Schleicher and Schüll, Dassel, FRG) at room temperature using a transfer cell (Hoefer Scientific, San Francisco, USA) and buffer containing $25 \mathrm{mM}$ Tris/glycine, 
$0.02 \%$ SDS and $10 \%(\mathrm{v} / \mathrm{v})$ methanol, $\mathrm{pH}$ 8.3. After protein transfer, nitrocellulose membrane (controlled by Ponceau $S$ staining) was blocked with $5 \%$ skimmed milk in TBS/Tween (10 mM Tris-HCI, pH 8.0, $150 \mathrm{mM} \mathrm{NaCl}, 0.05 \%$ Tween 20 ), incubated over night with rabbit anti-HSP-25 antibodies [44] in TBS/Tween and after extensive washing the antibodies were detected by means of alkaline phosphatase conjugated secondary antibodies employing a commercially available kit (ProtoBlot for Western Blot AP System, Promega Corporation, Madison, USA). Antibodies used for Western blotting were monoclonal antiubiquitin antibodies (working dilution $1: 500$ ) recognizing monomeric ubiquitin and ubiquitin-protein conjugates [31] and polyclonal antibodies against mouse HSP-25 [44] (working concentration I :750).

\section{Results and discussion}

\section{Cardiomyocytes in culture}

Under normal conditions, fetal cardiomyocytes in culture displayed rhythmic and synchronous contractions for several days. Figure 1 shows a microphotograph of spontaneously contractile fetal cardiomyocytes cultured for a week and stained with anti-actin antibodies. Actin was localized in cross striation in a very specific and regular manner with interspacing confirming one of the typical characteristics of cardiomyocytes [45]. We examined the purity of cardiomyocytes in culture on a regular basis by plating them on glass coverslips and growing them for $72 \mathrm{~h}$ prior to staining with anti-actin or anti-titin antibodies $[6,8]$. Serum deprivation of cardiomyocytes did not significantly alter the contractility without a sign of cellular damage up to $24 \mathrm{~h}$, the time taken prior to start of TNF- $\alpha$ incubation [6]. However, treatment of cardiomyocytes with TNF- $\alpha(25 \mathrm{ng} / \mathrm{ml})$ induced arrhythmias and cessation of spontaneous contractions in a concentration and time dependent manner. $8 \mathrm{~h}$ of TNF- $\alpha$ incubation resulted in complete cessation of spontaneous contractions in serum depleted cells. Previously, we have shown that higher doses of TNF- $\alpha(10,000$ units $/ \mathrm{ml})$ caused complete cessation of spontaneous contractions as early as $11 \mathrm{~min}$ after starting of treatment [6]. This inhibitory effect of TNF- $\alpha$ on contractility of cardiomyocytes was reversible upon incubation of cells in growth medium containing $10 \%$ of FCS.

When cells were treated for a longer period of time with a relatively low dose of TNF- $\alpha(25 \mathrm{ng} / \mathrm{ml})$, as in this study, 24 $h$ of incubation resulted in cellular necrosis leaving a number of floating dead cells in the culture medium. From these observations it can be inferred that TNF- $\alpha$ exerts a direct effect on contractility of cultured cardiomyocytes in a time and concentration dependent manner. TNF- $\alpha$ has been shown to have a reversible and directly concentration and time depend-

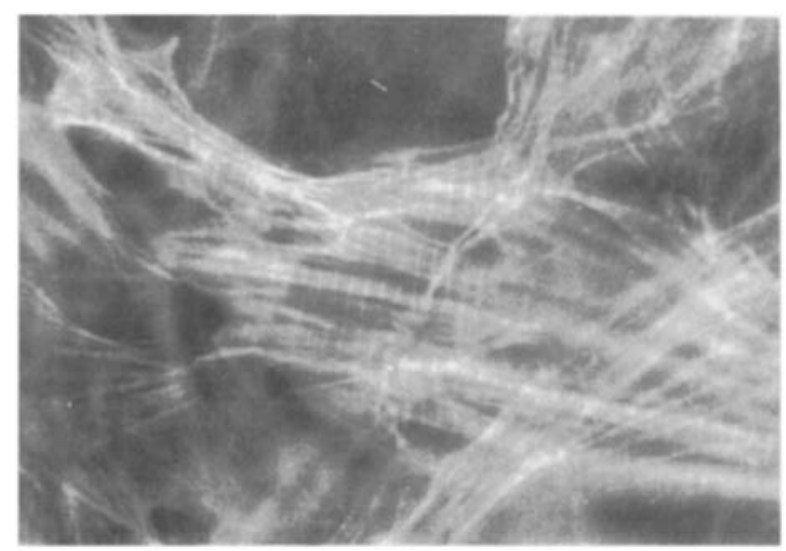

Fig. 1. Fluorescence microphotograph depicting actin microfilaments in cultured cardiomyocytes. Cardiomyocytes were grown on glass coverslips for a week, stained with anti-actin antibodies using rhodamine phalloidin and photographed using a fluorescence microscope equipped with epiellumination as described in Materials and methods. Note the actinstained microfilaments showing cross striation in a very specific and regular manner with interspacing.

ent negative inotropic effect on the myocardium $[2,5,6]$. In addition to such direct effects, TNF- $\alpha$ has been reported to be a potent inducer of cell surface adhesion molecules that facilitate adherence of neutrophils to cardiomyocytes and render them more susceptible to neutrophil mediated cellular injury $[5,46,47]$. Therefore, in pathophysiological conditions like myocardial infarction or ischemia, increased local myocardial expression may mimic tissue injury $[2,3]$. TNF$\alpha$ induced intracellular signaling cascade downstream to the ligand receptor binding in cardiomyocytes has been shown to be mediated via $\mathrm{G}_{\mathrm{ic}}$ and $\mathrm{G}_{\beta}$ proteins and adenylyl cyclase system [17] that may account for the depressed contractile state of cardiomyocytes. However, the intracellular mediators of TNF- $\alpha$ induced cytoprotective events are not yet characterized. Therefore, it is important to understand the intricacy of cellular mechanisms responsible for pleiotropic effects of TNF- $\alpha$ on cardiomyocytes and to determine whether this cytokine exerts its effect(s) directly or whether indirectly by stimulating and releasing other autocrine factors.

\section{Effect of TNF- $\alpha$ on HSP-27 expression}

Apart from its direct role in alteration of contractility of cardiomyocytes, that is whether TNF- $\alpha$ participates in cellular protective mechanisms, we evaluated a number of stress related genes in relation to TNF- $\alpha$. Figure 2 shows the densitometric analysis of the expression pattern of HSP-27 mRNA in cardiomyocytes in relation to TNF- $\alpha$. By Northern blot analysis we detected a mRNA species of $0.9 \mathrm{~kb}$ encoding HSP-27 in untreated (control, C) as well as TNF- $\alpha$ treated cardiomyocytes [7]. Expression of HSP-27 was drastically induced by TNF- $\alpha$ already as early as within $1 \mathrm{~h}$ of 


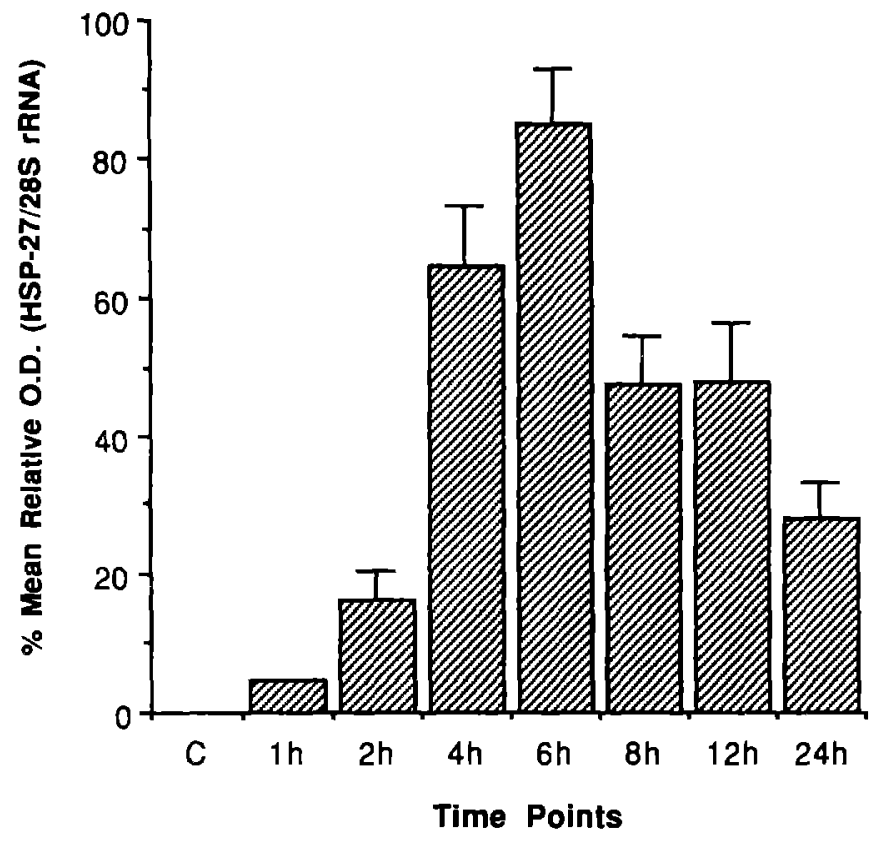

Fig. 2. Effect of TNF- $\alpha$ on HSP-27 gene expression. Bar graph showing quantitative analysis of the TNF- $\alpha$ induced HSP-27 mRNA expression. 15 $\mu \mathrm{g}$ of total RNA extracted from control (untreated) and TNF- $\alpha(25 \mathrm{ng} / \mathrm{ml})$ treated cardiomyocytes was hybridized with a rat $\mathrm{CDNA}$ insert encoding HSP-27. Filters were rehybridized with a radiolabeled cDNA probe for $28 \mathrm{~S}$ rRNA for reference purposes. Hybridization signals for mRNA bands of HSP-27 as well as of 28S rRNA were quantitated by video densitometry as described in the text. Data are means of the normalized signal \pm S.E.M. $(n=4)$ and expressed as \% mean relative O.D of HSP-27 and 28S rRNA hybridization signals.

incubation, reaching maximum levels at $6 \mathrm{~h}$. Thereafter the expression remained elevated until $12 \mathrm{~h}$ of incubation (Fig. 2). Earlier, TNF- $a$ had been shown to induce increased phosphorylation of HSP-27, but not accumulation of this protein [18-20]. In our experiments we also did not observe any significant accumulation of HSP-27 protein in cardiomyocytes as analyzed by Western blot analysis using anti-HSP-25 antibody [44], not even after $8 \mathrm{~h}$ of TNF- $\alpha$ incubation (Fig. 3). As positive and negative controls for the HSP-27 protein we included in our Western blots protein extracts from Ehrlich ascitus carcinoma as well as A431 cells, respectively (Fig. 3).

According to several previous reports, HSP-27 protein levels were unaltered in different cell types treated with TNF- $\alpha$ $[18,19]$. In this paper we show that TNF- $\alpha$ induces HSP-27 mRNA transcription but, for unknown reasons, this does not lead to an increase of HSP-27 protein levels. Therefore, increased mRNA levels seem to be a reservoir for quick HSP27 synthesis when cell needs it. In such a process, TNF- $\alpha$ guided phosphorylation of HSP-27 may play an important role. We do not know yet the role of phosphorylated HSP27 for cardiomyocytes but several possible explanations can be put forward. HSP-27 is a target of the MAPKAP kinase regulated signal transduction pathway [21]. Phosphorylated HSP-27 seems to differently influence actin polymerization

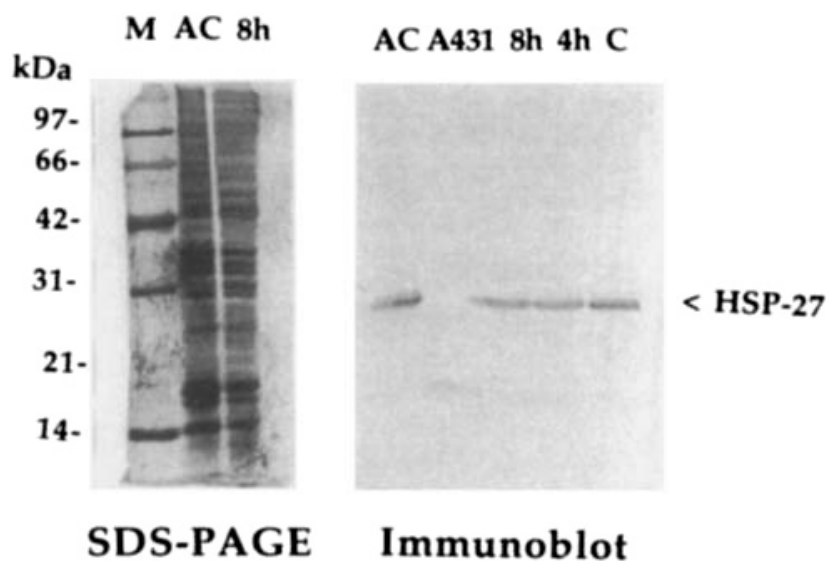

Fig. 3. Immunoblot analysis of HSP-27 accumulation after TNF- $\alpha$ treatment. Proteins extracted from TNF- $\alpha$ treated cardiomyocytes for various time points indicated at the top were fractionated on $15 \%$ SDS-PAGE and silver stained (left panel). $5 \mu \mathrm{g}$ protein from each sample were electrophoresed followed by electrotransfer and Western blot with antiserum recognizing HSP-27. Molecular weight markers (M) are indicated on the left in kilodaltons ( $\mathrm{kDa}$ ). $\mathrm{C}$, control; $\mathrm{AC}$, Ehrlich ascitus carcinoma cell extract, A431, A431 cell extract.

[48], a most likely very important process for heart muscle cells in particular upon cellular injury as for example due to ischemia, heat and TNF- $\alpha$. Furthermore, HSP-27 has a strong tendency to form aggregates or even high-molecular weight homopolymers [20], which may be intracellularly regulated by various processes (cytoplasmic and/or nuclear localization) which are not yet understood. Mehlen et al. [20] have shown that TNF- $\alpha$ induced expression and modifications in phosphorylation, intracellular distribution, and oligomerization of human HSP-27 that can be correlated to a reduced cytotoxicity of this cytokine in L929 cell. Therefore, phosphorylation and intracellular organization of HSP-27 in cardiomyocytes treated with TNF- $\alpha$, may be related to cytoprotective activity of this protein against the deleterious effects of this cytokine. In addition, a cytoprotective property of the small HSP family of proteins has also been attributed to their role to act as endogenous molecular chaperons giving rise to enhanced tolerance of cells to a stress condition [49].

\section{Effect of TNF- $\alpha$ on HSP-70 expression}

TNF- $\alpha$ induced the expression of HSP-70 gene in cardiomyocytes whereas, there was no detectable mRNA expression in control cardiomyocytes (Fig. 4). The mRNA signal of about $2.7 \mathrm{~kb}$ hybridizing to the HSP-70 cDNA probe was detectable at $2 \mathrm{~h}$ of incubation and the intensity of signal increased dramatically after $2 \mathrm{~h}$ of TNF- $\alpha$ incubation, then it remained increased until $12 \mathrm{~h}$, with maximal expression at $8 \mathrm{~h}$ [8]. TNF- $\alpha$ incubation of cardiomyocytes for $24 \mathrm{~h}$ resulted in decreased mRNA expression of HSP-70 (Fig 4). Several 


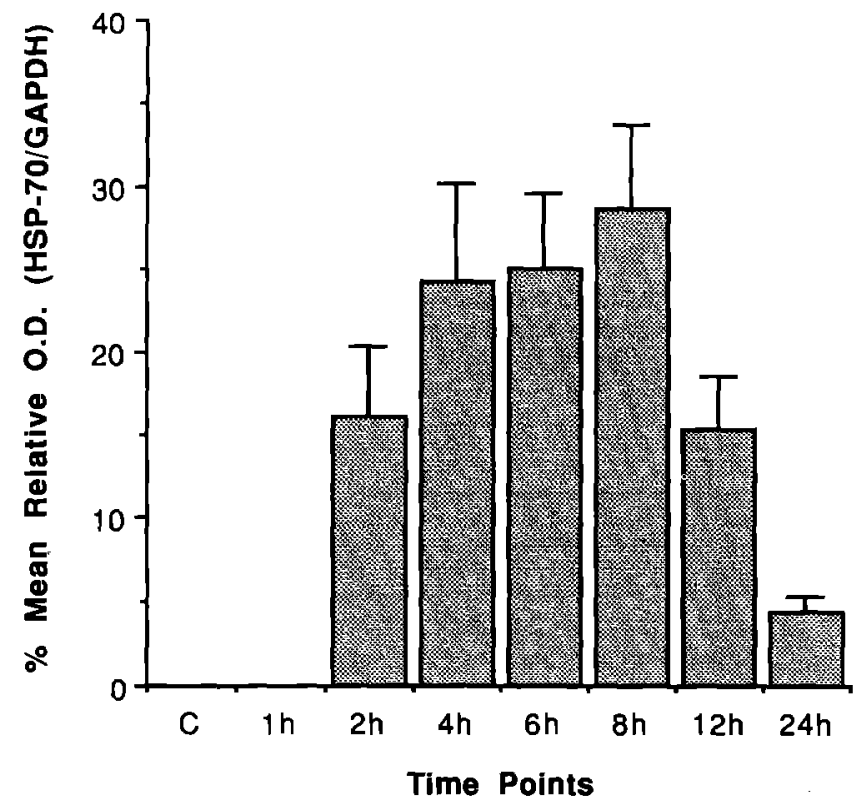

Fig. 4. Densitometric analysis of HSP-70 expression in relation to TNF$\alpha$. Bar graph showing quantitative analysis of the TNF- $\alpha$ induced HSP-70 mRNA expression. $15 \mu \mathrm{g}$ of total RNA extracted from control (untreated) and TNF- $\alpha(25 \mathrm{ng} / \mathrm{ml})$ treated cardiomyocytes was hybridized with a cDNA insert encoding human HSP-70. Filters were rehybridized with a radiolabeled cDNA probe for GAPDH for reference purposes. Hybridization signals for mRNA bands of HSP-70 as well as of GAPDH were quantitated by video densitometry as described in the text. Data are means of the normalized signal \pm S.E.M. $(n=4)$ and expressed as $\%$ mean relative O.D. of HSP -70 and GAPDH hybridization signals.

groups including our own have shown that myocardial ischemia and reperfusion induce the expression of HSPs that may be involved in the myocardial adaptation and cellular tolerance to ischemic stress $[25,28,29,34]$. Watanabe $e t$ al. [51] have found that TNF- $\alpha$ transfected cells expressed an increased amount of HSP-72 supporting a direct regulation of heat shock protein genes by this cytokine.

TNF- $\alpha$ that may participate in cellular injury has been shown to be produced in the postischemic and/or infarcted myocardium and to probably account for the enhanced circulating levels of this cytokine [1-3]. Therefore, it is important to understand the intricacy of cellular mechanisms responsible for the pleiotropic effects of TNF- $\alpha$ on the cardiomyocytes and to determine whether this cytokine exerts its effect(s) directly or whether indirectly by stimulating and releasing other autocrine and/or paracrine factors. It is believed that HSPs play an important role in transient adaptation in cellular activities, thereby coping with the stress period by protecting essential components of the cell and allowing the cell to recover from the stress [23-29]. Thus, elevated expression of HSPs in cardiomyocytes upon TNF$\alpha$ treatment is an indication for induction of heat shock response as the basis of transient cellular adaptation. TNF- $\alpha$ pretreatment for $24 \mathrm{~h}$ in rats has been found to be beneficial for the heart against ischemia-reperfusion injury and this beneficial effect could be mediated via the increased levels of MnSOD [4, 50]. In our cell culture model, the induction of $\mathrm{MnSOD}$, an enzyme involved in detoxification of superoxide anions in mitochondria in response to TNF- $\alpha$, could also not be ruled out.

\section{Effect of TNF- $\alpha$ on ubiquitin expression}

We examined TNF- $\alpha$ treated cultured cardiomyocytes for expression of ubiquitin and ubiquitin-conjugates in order to evaluate the extent of cellular protein damage by this cytokine. Multiple mRNA bands encoding the monomer as well as polymers of ubiquitin were detected in cardiomyocytes [8]. Steady state mRNA levels of ubiquitin were drastically induced ( $>10$ fold versus untreated cells) by TNF- $\alpha$ being maximal at $6 \mathrm{~h}$ of stimulation and thereafter expression of this stress gene declined but remained elevated as compared to control (Fig. 5). Ubiquitin is a highly conserved protein found in all cell types contributing to non-lysosomal and ATP dependent cytosolic proteolysis $[25,30,31,36]$. In a porcine model of myocardial ischemia and reperfusion, we have earlier reported that ubiquitin mRNAs as well as monomeric and conjugated ubiquitin protein levels were enhanced in the postischemic heart [25]. Myocardial ischemia is known to produce a number of intracellular changes within cardio-

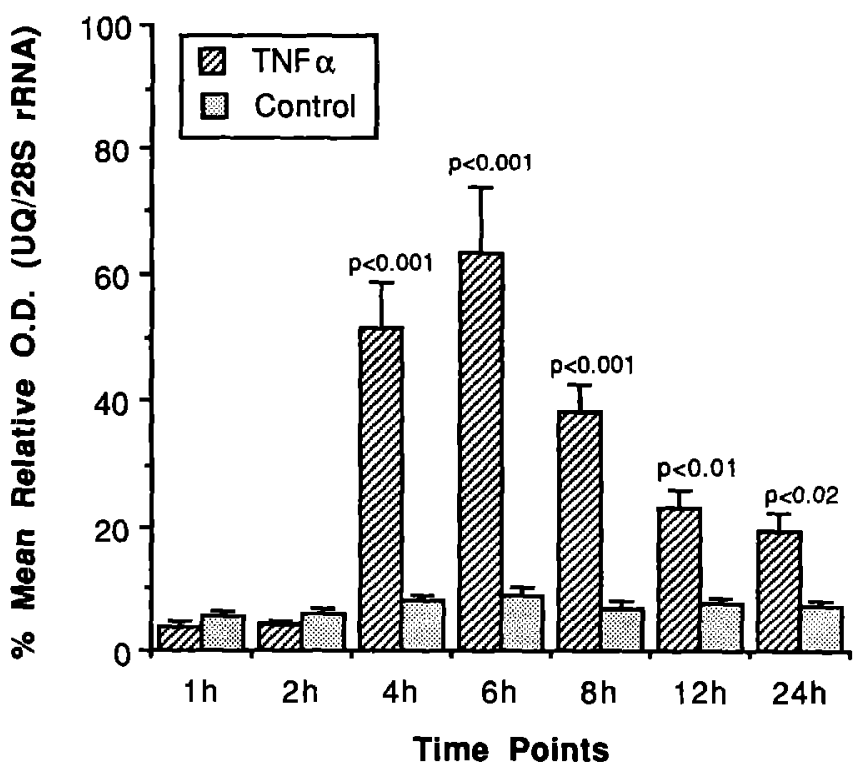

Fig. 5. Densitometric analysis of ubiquitin expression in relation to TNF$\alpha$. Bar graphs showing quantitative analysis of the TNF- $\alpha$ induced ubiquitin mRNA expression. Hybridized mRNA bands of ubiquitin as well as of 28S rRNA blots were quantitated by video densitometry as described in the text. Data are means of the normalized signal \pm S.E.M. $(n=4)$ and expressed as \% mean relative O.D of ubiquitin and $28 \mathrm{~S}$ rRNA hybridization signals. 


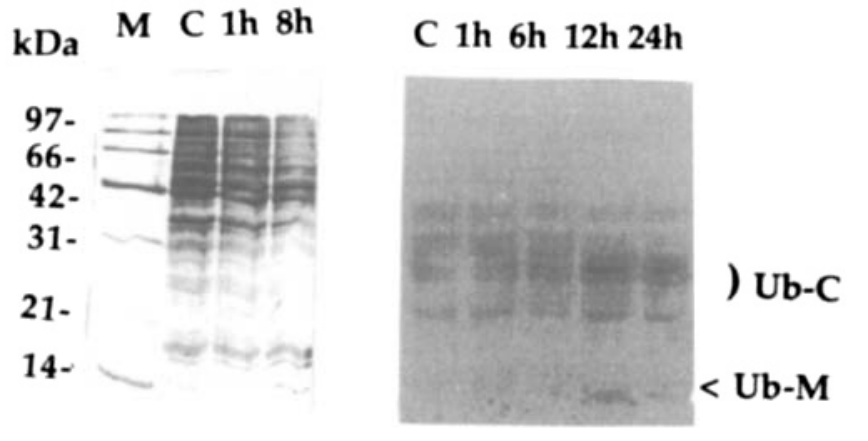

\section{SDS-PAGE Immunoblot}

Fig. 6. Immunoblot analysis of ubiquitin and ubiquitin-protein conjugates after TNF- $\alpha$ treatment. Protein staining of SDS-PAGE by Coomassie (left panel). Samples ( $15 \mu \mathrm{g}$ protein each) were taken from cells treated with TNF- $\alpha$ for time points given at the top and separated by $15 \%$ SDS-PAGE followed by electrotransfer and Western blot with monoclonal anti-ubiquitin antibodies recognizing ubiquitin-protein conjugates (right panel). Molecular weight markers $(\mathrm{M})$ are indicated on the left in kilodaltons $(\mathrm{kDa}) . \mathrm{Ub}-\mathrm{M}$, ubiquitin monomer; UB-C, ubiquitin-protein conjugates; $\mathrm{C}$, control;

myocytes including increased cellular calcium levels, free radical production, decreased intracellular $\mathrm{pH}$, decreased ATP and glucose levels, etc. These cellular alterations lead to metabolic or hypoxic stress and result in cellular injury that may be characterized by denaturation and/or disturbance in three dimensional structure of many proteins. Medina et al. [32] have demonstrated that increased protein degradation in muscle atrophy caused by starvation and denervation is due to activation of the ubiquitin system for proteolysis as they found increased levels of polyubiquitin and proteasome mRNAs. Enhanced expression of ubiquitin in cardiomyocytes treated with TNF- $\alpha$ is an indication of cellular protein damage. Figure 6 depicts increased intensity and number of ubiquitin-protein conjugates in TNF- $\alpha$ treated cells as compared to control. Recently, it has been shown that an acute intravenous administration of TNF- $\alpha(100 \mu \mathrm{g} / \mathrm{kg}$ body weight) in rats resulted in a time dependent increase in the levels of both free and conjugated ubiquitin in skeletal muscle [52]. Our results on ubiquitin expression indicate that TNF- $\alpha$ induces the non-lysosomal protein degradation pathway for clearance of damaged or denatured proteins in cardiomyocytes.

\section{Conclusion}

We have shown that TNF- $\alpha$ is a potent inducer of heat shock protein genes in cardiomyocytes. Induction of genes conferring resistance to the cytotoxic property of TNF- $\alpha$ may provide a means to cardiomyocytes for self-defense under pathophysiological conditions. Hence, the induced expression of cytoprotective molecules such as stress proteins (HSP-
27, HSP-70 and ubiquitin) in response to TNF- $\alpha$ may activate protective as well as repair mechanisms in cardiomyocytes for making them more resistant toward a subsequent challenge such as ischemia. It appears that TNF$\alpha$ on the one hand mimics cellular injury in the heart and on the other hand simultaneously stimulates synthesis of vital proteins like HSPs and other proteins (for instance MnSOD) making TNF- $\alpha$ an interesting and relevant cytokine for the cardiovascular system. Furthermore, the ubiquitin system could play an important role in cytosolic degradation of damaged proteins in TNF- $\alpha$ treated cardiomyocytes where HSPs may counteract the proteolytic events and preserve vital proteins. We conclude that the enhanced transcription of HSPmRNAs in response to TNF- $\alpha$ in cardiomyocytes may be an important basis for activation of protective and defense mechanisms contributing to cardiac protection, for example against ischemia.

\section{Acknowledgements}

The first author is thankful to Prof. Dr. W. Schaper, M.P.I., Bad Nauheim, for supporting the initial stage of this study.

\section{References}

1. Maury CP, Tempo AM: Circulating tumor necrosis factor- $\alpha$ (cachectin) in myocardial infarction. Am J Pathol 139: 709-715, 1989

2. LeferAM, Tsao P, Aoki N, Palladino MJ: Mediation of cardioprotection by transforming growth factor-b. Science 249: 61-64, 1990

3. Herskowitz A, Choi S, Ansari AA, Wesselingh S: Cytokine mRNA expression in postischemic/reperfused myocardium. Am I Pathol 146: $419-428,1995$

4. Eddy LJ, Goeddel DV, Wong GH: Tumor necrosis factor- $\alpha$ pretreatment is protective in a rat model of myocardial ischemia-reperfusion injury. Biochem Biophys Res Comm 184: 1056-1059, 1992

5. Yokoyama T, Vaca L, Rossen RD, Durante, W, Hazarika P, Mann DL: Cellular basis for the negative inotropic effects of tumor necrosis factor- $\alpha$ in the adult mammalian heart. J Clin Invest 92: 2303-2012, 1993

6. Weisensee D, Bereiter HJ, Schoeppe W, Löw-Friedrich I: Effects of cytokines on the contractility of cultured cardiac myocytes. Int $J$ Immunopharmacol 15: 581-587, 1993

7. Löw-Friedrich I, Weisensee D, Mitrou P, Schoeppe W: Cytokines induce stress protein formation in cultured cardiac myocytes. Basic Res Cardiol 87: 12-18, 1992

8. Sharma HS, Weisensee D, Löw-Friedrich I: Tumor necrosis factor- $\alpha$ induced cytoprotective mechanisms in cardiomyocytes: Analysis by mRNA phenotyping. Ann NY Acad Sci, 1996 (in press)

9. Beyaert R, Fiers W: Molecular mechanisms of tumor necrosis factorinduced cytotoxicity. What we do understand and what we do not. [Review]. FEBS Lett 340: 9-16, 1994

10. Tracey KJ, Cerami A: Tumor necrosis factor: A pleiotropic cytokine and therapeutic target. [Review]. Ann Rev Med 45: 491-503, 1994

11. Frater-Schröder M, Risau W, Hallmann R, Gautschi P, Böhlen P: Tumor necrosis factor type $\alpha$, potent inhibitor of endothelial cell growth 
in vitro, is angiogenic in vivo. Proc Natl Acad Sci (USA) 84: 52775281,1987

12. Strieter RM, Kunkel SL, Bone RC: Role of tumor necrosis factor- $\alpha$ in disease states and inflammation. [Review] Crit Care Med 21: 447463,1993

13. Wiegmann K, Schutze S, Kampen E, Himmler A, Machleidt T, Kronke M: Human 55-kDa receptor for tumor necrosis factor coupled to signal transduction cascades. J Biol Chem 267: 17997-18001, 1992

14. Tartaglia LA, Weber RF, Figari IS, Reynolds C, Palladino MJ, Goeddel DV: The two different receptors for tumor necrosis factor mediate distinct cellular responses. Proc Natl Acad Sci (USA) 88: 9292-9296, 1991

15. Heller RA, Kronke $M$ : Tumor necrosis factor receptor-mediated signaling pathways. [Review] J Cell Biol 126: 5-12, 1994

16. Rothe J, Gehr G, Loetscher H, Lesslauer W: Tumor necrosis factor receptors-structure and function. [Review]. Immunol Res 11: 81-90, 1992

17. Reithmann C, Gierschik P, Werdan K, Jakobs KH: Tumor necrosis factor- $\alpha$ up-regulates $\mathrm{Gi}$ alpha and $\mathrm{Gi}$ beta proteins and adenylyl cyclase responsiveness in rat cardiomyocytes. Eur J Pharmacol 206: 53 60, 1991

18. Kaur P, Welch WJ, Saklatvala J: Interleukin 1 and tumour necrosis factor increase phosphorylation of the small heat shock protein. Effects in fibroblasts, Hep G2 and U937 cells. FEBS Lett 258: 269-273, 1989

19. Vietor I, Vilcek J: Pathways of heat shock protein 28 phosphorylation by TNF in human fibroblasts. Lymphokine Cytokine Res 13: 315323,1994

20. Mehlen P, Mehlen A, Guillet D, Preville X, Arrigo A-P: Tumor necrosis factor- $\alpha$ induces changes in the phosphorylation, cellular localization, and oligomerization of human HSP 27, a stress protein that confers cellular resistance to this cytokine. J Cell Biochem 58: 248-259, 1995

21. Engel K, Ahlers A, Brach MA, Herrmann F, Gaestel M: MAPKAP Kinase 2 is activated by heat shock and TNF- $\alpha$ : In vivo phosphorylation of small heat shock protein results from stimulation of the MAP Kinase cascade. J Cell Biochem 57: 321-330, 1995

22. Sharma HS, Weisensee D, Löw-Friedrich 1, Schoeppe W, Schaper W: Vascular endothelial growth factor expression in cardiac myocytes in vitro and its upregulation by tumor necrosis factor-a. J Cell Biochem 17D: 216,1993

23. Welch WJ: Mammalian stress response: Cell physiology, structure/function, of stress proteins, and implications for medicine and disease. Physiol Rev 72: 1063-1081, 1992

24. Mestril R, Dillmann WH: Heat shock proteins and protection against myocardial ischemia. [Review]. J Mol Cell Cardiol 27: 45-52, 1995

25. Andres J, Sharma HS, Knöll R, Stahl J, Sassen LMA, Verdouw PD, Schaper W: Expression of heat shock proteins in the normal and stunned porcine myocardium. Cardiovasc Res 27: 1421-1429, 1993

26. Schlesinger M: Heat shock proteins. J Biol Chem 265: 1211 1-12114, 1990

27. Ciocca DR, Oesterreich S, Chamness GC, McGuire WL, Fuqua SA: Biological and clinical implications of heat shock protein 27,000 (HSP27): a review. [Review]. J Natl Cancer Inst 85: 1558-1570, 1993

28. Iwaki $\mathrm{K}$, Chi SH, Dillmann WH, Mestril R: Induction of HSP-70 in cultured rat neonatal cardiomyocytes by hypoxia and metabolic stress. Circulation 87: 2023-2032, 1993

29. Sharma HS, Snoeckx LH, Sassen LMA, Knoel R, Andres J, Verdouw PD, Schaper W: Expression and immunohistochemical localization of heat shock protein-70 in preconditioned porcine myocardium. Ann NY Acad Sci 723: 491-494, 1993

30. Jentsch S: Ubiquitin-dependent protein degradation: A cellular perspective. Trends Cell Biol 2: 98-103, 1992

31. Hayashi T, Takada K, and Matsuda M: Post-transient ischemia increase in ubiquitin conjugates in the early reperfusion. Neuroreport 3:519 520,1992
32. Medina R, Wing SS, Goldberg AL: Increase in levels of polyubiquitin and proteasome mRNA in skeletal muscle during starvation and denervation atrophy. Biochem J 307: 631-637, 1995

33. Sharma HS, Maulik N, Das DK, Gho BCG, Verdouw PD; Coordinated Expression of heme oxygenase-1 and ubiquitin in the porcine heart subjected to ischemia and reperfusion. Mol Cell Biochem, 157: $111-116,1996$

34. Heads RJ, Yellon DM, Latchman DS: Differential cytoprotection against heat stress or hypoxia following expression of specific stress protein genes in myogenic cells. J Mol Cell Cardiol 27: 1669-1678, 1995

35. Knowlton AA: The role of heat shock proteins in the heart. J Mol Cell Cardiol 27: 121-131, 1995

36. Einspanier R., Sharma HS, Scheit KH: An mRNA encoding polyubiquitin in porcine corpus luteum: Identification by cDNA cloning and sequencing. DNA 6: 395-400, 1987

37. Brand T, Sharma HS, Fleischmann KE, Duncker DJ, McFalls EO, Verdouw PD, Schaper, W: Proto-oncogene expression in porcine myocardium subjected to ischemia and reperfusion. Circ Res 71: 13511360,1992

38. Chomczynski P, Sacchi N: Single step method of RNA isolation by acid guanidinium thiocyanate-phenol-chloroform extraction. Anal Biochem 162: 156-159, 1987

39. Laemmli U: Cleavage of structural proteins during the assembly of the head of bacteriophage T4. Nature 227: $680-685,1970$

40. Wu B, Hunt C, and Morimoto R: Structure and expression of the human gene encoding major heat shock protein HSP70. Mol Cell Biol 5: $330-341,1985$

41. Hickey E, Brandon SE, Sadis S, Smale G, Weber LA: Molecular cloning of sequences encoding the human heat-shock proteins and their expression during hyperthermia. Gene 43: 147-154, 1986

42. Lowry O, Rosenbrough N, Farr A, Randall R: Protein measurements with the folin phenol reagent. J Biol Chem 193: 265-275, 1951

43. Towbin $\mathrm{H}$, Staehelin $\mathrm{T}$, Gordon J: Electrophoretic transfer of proteins from polyacrylamide gels to nitrocellulose sheets: Procedure and some applications. Proc Natl Acad Sci (USA) 76: 4350-4354, 1979

44. Gernold M, Knauf U, Gaestel M, Stahl J, Kloetzel PM: Developmental and tissue specific distribution of mouse small heat shock protein HSP25. Dev Gen 14: 103-111, 1993

45. Schaper J, Hein S, Brand T, Schaper W: Contractile proteins and the cytoskeleton in isolated rat myocytes. J Appl Cardiol 4: 423-429, 1989

46. Vaddi K, Nicolini FA, Mehta P, Mehta, IL: Increased secretion of tumor necrosis factor- $\alpha$ and interferon-gamma by mononuclear leukocytes in patients with ischemic heart disease. Relevance in superoxide anion generation. Circulation 90: 694-699, 1994

47. Ikeda U, Ikeda M, Kano S, Shimada K: Neutrophil adherence to rat cardiac myocyte by proinflammatory cytokines. J Cardiovas Pharmacol 23: 647-652, 1994

48. Benndorf R, Hayeß K, Ryazantsev S, Wieske M, Behlke J, Lutsch G: Phosphorylation and supramolecular organization of murine small heat shock protein HSP25 abolish its actin polymerization-inhibiting activity. J Biol Chem 269: 20780-20784, 1994

49. Jacob U, Gaestel M, Engel K, Buchner $\mathbf{J}$; Small heat shock proteins are molecular chaperons. J Biol Chem 268: 1517-1520, 1993

50 . Wong GH, Goeddel DV: Induction of manganous superoxide dismutase by turnor necrosis factor: possible protective mechanism. Science 242: $941-944,1988$

51. Watanabe N, Akiyama S, Tsuji N, Sasaki H, Yamauchi N, Okamoto T, Kobayashi D, Niitsu Y: Induction of synthesis of heat shock protein 72 in tumor necrosis factor gene transduced cells. Jpn J Cancer Res 85: 997-999, 1994

52. Garcia MC, Agel1 N, Llovera M, Lopez SF, and Argiles JM: Tumour necrosis factor-alpha increases the ubiquitinization of rat skeletal muscle proteins. FEBS Lett 323: 211-214, 1993 